\title{
Functional analysis of the cellulose gene of the pine wood nematode, Bursaphelenchus xylophilus, using RNA interference
}

\author{
H.B. Ma ${ }^{1,2}$, Q. Lu ${ }^{1}$, J. Liang ${ }^{1}$ and X.Y. Zhang ${ }^{1}$ \\ ${ }^{1}$ Key Laboratory of Forest Protection, State Forestry Administration, \\ Research Institute of Forest Ecology, Environment and Protection, \\ Chinese Academy of Forestry, Beijing, China \\ ${ }^{2}$ Research Institute of Tropical Forestry, Chinese Academy of Forestry, \\ Guangzhou, China \\ Corresponding author: X.Y. Zhang \\ E-mail: xyzhang@caf.ac.cn
}

Genet. Mol. Res. 10 (3): 1931-1941 (2011)

Received March 3, 2011

Accepted June 30, 2011

Published August 30, 2011

DOI http://dx.doi.org/10.4238/vol10-3gmr1367

\begin{abstract}
Cellulases are pathogenic substances suspected to be responsible for the development of the early symptoms of nematode disease. The pine wood nematode, Bursaphelenchus xylophilus (Parasitaphelenchidae), is the causal agent of pine wilt disease, which kills millions of pine trees. We used RNA interference (RNAi), a reverse genetic tool, to analyze the function of the endo- $\beta-1,4$-glucanase gene of B. xylophilus, which causes the most serious forest tree disease in China and the rest of eastern Asia. Silencing of this gene was detected through real-time PCR and cellulase activity assays after soaking for $24 \mathrm{~h}$ in dsRNA. The cellulase gene silencing effects differed among various siRNAs. The propagation and dispersal ability of these nematodes decreased when the endo- $\beta$-1,4-glucanase gene was silenced. It is important to select an effective siRNA before performing an RNAi test.
\end{abstract}

Key words: Bursaphelenchus xylophilus; Endo- $\beta-1,4-$ glucanase; RNA interference 


\section{INTRODUCTION}

The nematode Bursaphelenchus xylophilus is the causal agent of pine wilt disease (Tokushige and Kiyohara, 1969; Kiyohara and Tokushige, 1971; Mamiya and Kiyohara, 1972), one of the most serious pine diseases in China (Zhang and Luo, 2006) and other regions of east Asia, causing the death of millions of pine trees. This nematode is carried from wilt-killed to healthy tree by the beetle Monochampus alternatus (Mamiya and Enda, 1972; Mamiya, 1983). There is no effective method of control of its dispersion and disease, although its biology has been known for more than 30 years.

The pathogenic mechanisms of B. xylophilus are still not completely understood. The enzyme theory, the cavitation theory and the toxin theory are the three main explanations (Odani et al., 1985; Kuroda, 1989). Cell-wall-degrading enzymes play a very important role in the interaction of B. xylophilus and pine trees. Cellulase released by the nematode is one of the pathogenic substances suspected to be responsible for the development of the early symptoms. Several cellwall-degrading enzyme gene cloning and function analyses were performed for explaining the parasitic mechanism of B. xylophilus (Kikuchi et al., 2004, 2005, 2006, 2007).

RNA interference (RNAi) was first described by Fire et al. (1998) in Caenorhabditis elegans, as a tool for analyzing gene function in vitro. Since then, RNAi has been used to investigate pathogenicity-related genes in plant parasitic cyst- and root-knot nematodes (Rosso et al., 1999; Urwin et al., 2002; Fanelli et al., 2005; Chen et al., 2005; Huang et al., 2006). Various methods have been developed for uptake of double-stranded RNA (dsRNA), including microinjection with dsRNA, soaking worms in a dsRNA solution, and feeding worm bacteria that express dsRNA; these are the three most frequent RNAi methods (Park et al., 2008).

We tested the efficiency of RNAi for silencing the pathogenicity-related gene endo- $\beta$ 1,4-glucanase in B. xylophilus.

\section{MATERIAL AND METHODS}

\section{Biological material}

The B. xylophilus isolate BxZJ02 was first obtained with Baermann funnels from Pinus massoniana in Zhoushan city, Zhejiang province, China, in August 2003. Groups of 10 nematodes were cultured on potato dextrose agar (PDA) plates covered with the mycelium of Botrytis cinerea for 10 days at $25^{\circ} \mathrm{C}$. Nematodes of various developmental stages were separated from the $B$. cinerea hyphae in a Baermann funnel for $6 \mathrm{~h}$ at $25^{\circ} \mathrm{C}$, placed into $10-\mathrm{mL}$ tubes, and centrifuged at $2000 \mathrm{rpm}$ for $5 \mathrm{~min}$. The nematodes were washed five to six times with M9 buffer (Rosso et al., 2005) to remove any trace of $B$. cinerea mycelium, and then incubated at $20^{\circ} \mathrm{C}$ at $175 \mathrm{rpm}$ for $24 \mathrm{~h}$; the nematodes were then maintained at $-70^{\circ} \mathrm{C}$ until use.

\section{Total RNA preparation and cDNA synthesis}

The frozen nematodes were ground in liquid nitrogen in a mortar. The total RNA was extracted from the resulting powder using an RNeasy Mini Kit (QIAGEN, China). The total RNA quality was detected using $1 \%$ agarose gel electrophoresis, and the concentration and purity were detected using an ultraviolet spectrophotometer. The RNA was reverse-transcribed using a cDNA synthesis kit (DINGGUO, China), according to manufacturer recommendations. 


\section{Small interfering RNA (siRNA) oligo synthesis and fluorescent dye-labeled siRNA}

The cDNA fragments encoding for the endo- $\beta$-1,4-glucanase (EU660207 and AB179544) were used to design the siRNA sequences with the siRNA Design Tools program (http://www.ambion.com and http://www.promega.com). The siRNA oligos were synthesized chemically by Shanghai GenePharma Co. Ltd., and the negative control siRNA was FAM labeled by fluorescent dye, which can be easily observed with a fluorescence microscope to determine transfection efficiency and thereby optimize transfection conditions. The siRNA oligos were as shown in Table 1 ( 5 ' to $3^{\prime}$ sequence).

\begin{tabular}{lll}
\multicolumn{2}{c}{ Table 1. The siRNA oligos used in this experiment. } & \\
\hline siRNA oligos & Sense & Anti-sense \\
\hline siRNA $^{15}$ & 5'-UCU UGU GUU UCU GGC CGU Utt-3' & 5'-AAC GGC CAG AAA CAC AAG Att-3' \\
siRNA & '75 & 5'-UUU CCG GCC AAU UUC ACG Gtt-3' \\
siRNA & 5'-CCG UGA AAU UGG CCG GAA Att-3' & 5'-UGG ACC ACG AAU UUC UUG Ctt-3' \\
siRNA & 581 & 5'-GCA AGA AAU UCG UGG UCC Att-3' \\
siRNA $^{\text {con }}$ & 5'-GGU UCA AGA ACG CCG ACA Att-3' & 5'-UUG UCG GCG UUC UUG AAC Ctt-3' \\
\hline
\end{tabular}

\section{Pine wood nematodes soaking and transfection}

The mixed-stage nematodes were collected from the PDA plate and washed with M9 buffer five to six times. The worms were centrifuged at $3000 \mathrm{~g}$ and washed with DEPC water three times. For each silencing assay, $150 \mu \mathrm{L}$ of the nematode suspension (about 150,000 nematodes) or control buffer was placed into a $200-\mu \mathrm{L}$ siRNA solution and incubated at $175 \mathrm{rpm}$ for 24 $\mathrm{h}$ at $20^{\circ} \mathrm{C}$. The negative-control dsRNA uptake was examined under a fluorescence microscope.

\section{mRNA expression analysis}

For each silencing assay, nematodes were obtained for RNA extraction, as described above, after soaking in a dsRNA solution. Real-time polymerase chain reaction (PCR) was performed using a TaqMan ${ }^{\circledR}$ Universal PCR Master Mix kit (ABI, Foster City, CA, USA) and primers for the endo- $\beta$-1,4-glucanase and $18 \mathrm{~S}$ rRNA gene (as a control) in a thermo cycler (ABI 9700) with the SDS software. Primers used for amplification of endo- $\beta$-1,4-glucanase were 5'-ATTCGCGGCCGTGAAA-3' and 5'-CGTAGCAAGAGCAGCACCAA-3', and the TaqMan probe was 5'-FAM-TGGCCGGAAAGCAGGAGTCG-TAMRA-3'.

Primers for amplification of $18 \mathrm{~S}$ rRNA gene were 5'-GGATTGCAACGCAGGTATG G-3' and 5'-AAAAACATGCAAAATGCAAGCA-3', and the TaqMan probe was 5'-FAM-TC CACCCTCTGGGTGCGTACT-TAMRA-3'.

\section{Effect of RNAi on B. xylophilus feeding and reproduction}

One hundred nematodes soaked in dsRNA solution for $24 \mathrm{~h}$ were transferred onto a PDA plate with $B$. cinerea and cultured at $25^{\circ} \mathrm{C}$ for 10 days. Then, the worms were washed from the plate and the nematodes were counted. Some of the nematodes were tested for RNAi effects after soaking in dsRNA solution, using a fluorescence microscope. 


\section{Effect of RNAi on B. xylophilus dispersal}

Four-year-old living branches, about $1 \mathrm{~cm}$ in diameter, were taken from healthy Pinus thunbergii trees growing on the campus of the Chinese Academy of Forestry in Beijing and the cut end placed in water for transport to the lab. The branches were cut into three $5-\mathrm{cm}$ long sections under water. The water was then removed with tissue paper from the bark surface of the branch sections. Individual 5-cm long sections were placed upright in $50-\mathrm{mL}$ centrifuge tubes containing $1 \mathrm{~mL}$ water. A $200-\mu \mathrm{L}$ aliquot containing 200 nematodes was pipetted onto the upper cut end of the individual branch sections and the sections were kept at $25^{\circ} \mathrm{C}$ in the dark. The number of nematodes that emerged from the bottom end of the branch section into the water was determined each $6 \mathrm{~h}$ (Togashi and Matsunaga, 2003).

\section{Enzyme activity assay}

Endo- $\beta$-1,4-glucanase, exo- $\beta-1,4$-glucanase and $\beta$-glycosidase activity were determined by the hydrolysis of $400 \mu \mathrm{L} 1 \%$ sodium carboxymethyl cellulose, microcrystalline cellulose and salicylic acid in $100 \mathrm{mM}$ sodium acetate buffer, $\mathrm{pH} 4.6$, at $50^{\circ} \mathrm{C}$ for $1 \mathrm{~h}$. Then, 400 $\mu \mathrm{L} 3 \mathrm{M}$ sodium hydroxide and $800 \mu \mathrm{L}$ DNS were added to stop the reaction, by boiling in a water bath for $8 \mathrm{~min}$ and quick cooling to room temperature (Li et al., 2005). The absorbance at $490 \mathrm{~nm}$ was measured (a standard assay). One unit of endo- $\beta-1,4$-glucanase activity is defined as the amount of $1 \mathrm{~mL}$ enzyme that yields $1 \mu \mathrm{g}$ glucose in $1 \mathrm{~min}$ at $50^{\circ} \mathrm{C}$.

\section{RESULTS}

\section{dsRNA uptake}

A fluorescent signal was used as a tracer for uptake efficiency. After $24 \mathrm{~h}$ soaking in the dsRNA labeled with FITC solution, an accumulation of dsRNA was clearly observed at the intestine wall (Figure 1A). The lipid vesicles of the nematodes appeared auto-centralized at the intestine wall and were densely and regularly arranged (Figure 1B), while the nematodes soaked in M9 buffer were loosely and irregularly organized (Figure 1C). Under the test conditions, dsRNA was transfected effectively into the nematodes and RNAi could be performed by direct soaking in the dsRNA solution.

\section{Feeding and propagation of $B$. xylophilus after soaking in dsRNA}

The effect of RNAi on the propagation of B. xylophilus was tested on PDA plates previously inoculated with $B$. cinerea. The various dsRNA treatments resulted in different feeding speeds of B. xylophilus (Figure 2A-E). The results showed that nematode treatment with siRNA ${ }^{15}$ and siRNA ${ }^{275}$ significantly reduced the propagation of $B$. xylophilus compared with siRNA ${ }^{581}$ and siRNA ${ }^{\text {con }}$ treatment $(\mathrm{P}<0.05)$. The number of nematodes in the siRNA ${ }^{\text {con }}$ treatment was about 47,580 while the number of nematodes in the siRNA ${ }^{275}$ treatment was only 18,400 after 10 days (Figure 3). We found that feeding and propagation of B. xylophilus worms were influenced by soaking in the dsRNA solution. 


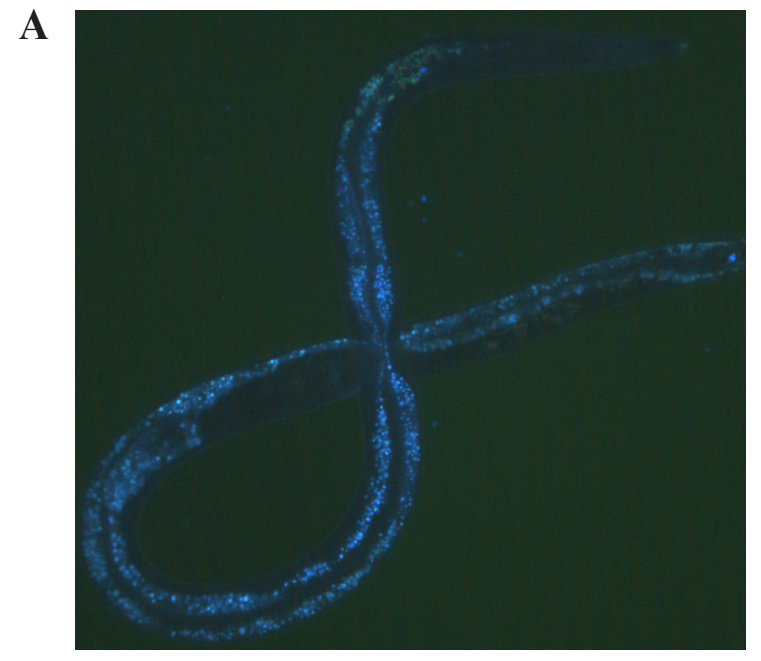

B

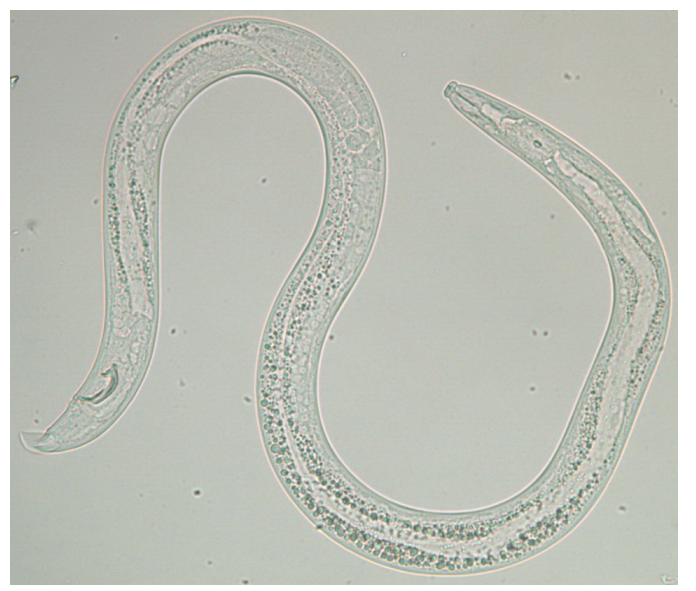

C

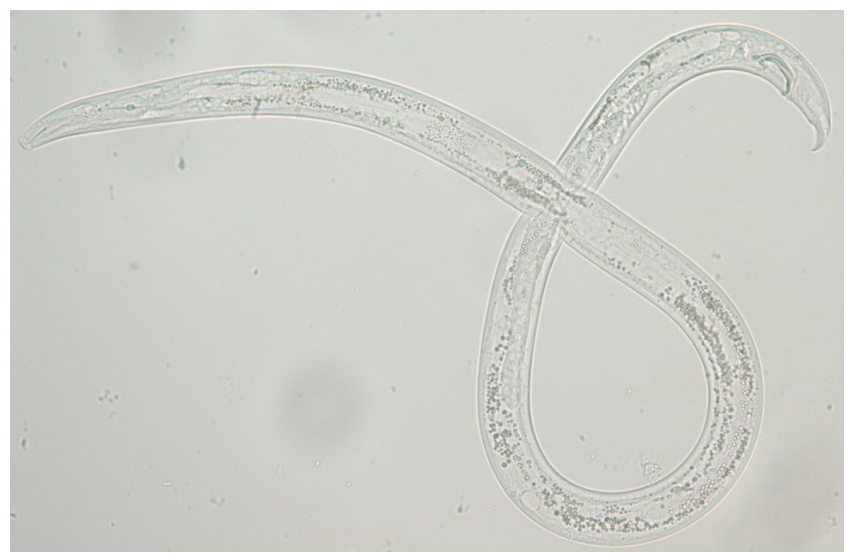

Figure 1. Phenotype of Bursaphelenchus xylophilus after soaking in dsRNA. A. Under fluorescence microscopy. B. and C. Under optical microscopy. 
A

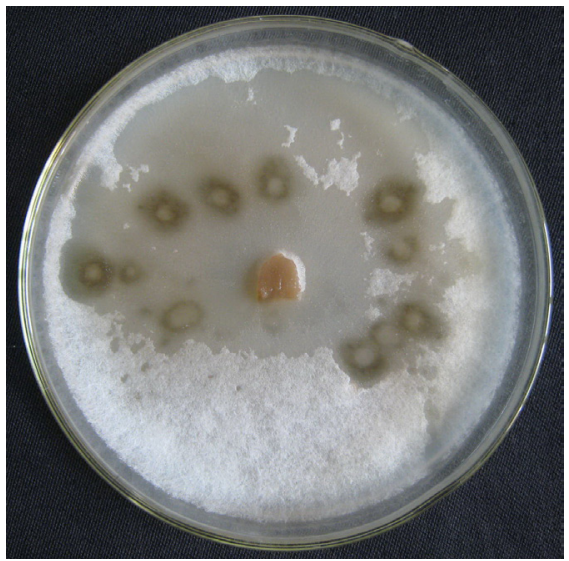

B

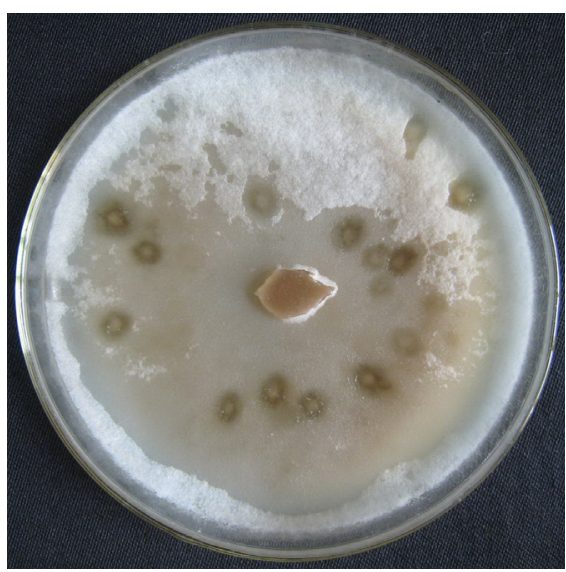

$\mathrm{C}$

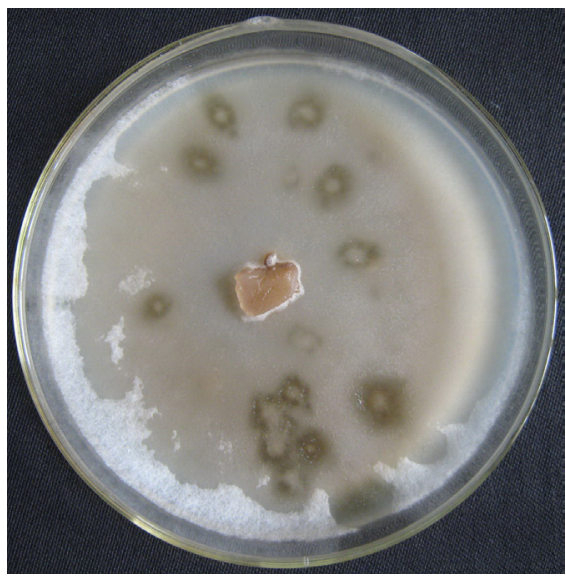

D

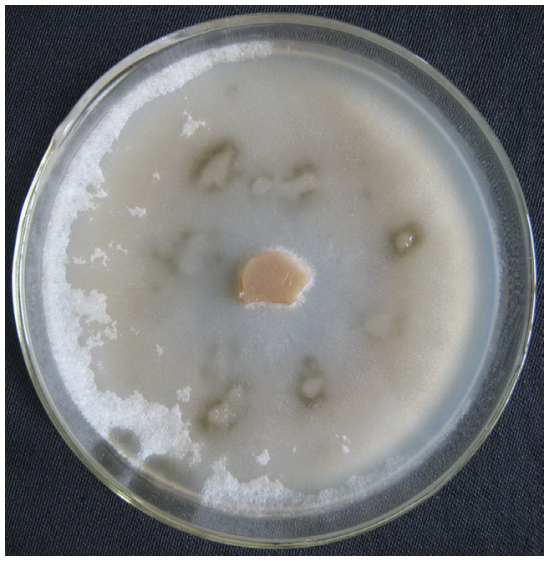

E



Figure 2. Feeding of Bursaphelenchus xylophilus five days after inoculation on Botrytis cinerea. A. Nematodes soaked in siRNA ${ }^{15}$ solution. B. Nematodes soaked in siRNA ${ }^{275}$ solution. C. Nematodes soaked in siRNA ${ }^{356}$ solution. D. Nematodes soaked in siRNA ${ }^{581}$ solution. E. Nematodes soaked in siRNA ${ }^{\text {con }}$ solution. 




Figure 3. Propagation (number) of Bursaphelenchus xylophilus washed from the PDA plate of Botrytis cinerea after soaking in different siRNA solutions. Bars showed standard error of the mean. Significant differences were found between the treatments with siRNAs and the control $(\mathrm{P}<0.05)$.

\section{mRNA expression in B. xylophilus worms after soaking in dsRNA}

Real-time PCR was performed to test the effect of RNAi on the mRNA level of endo- $\beta-1,4$-glucanase and its expression/inhibition. The 18sRNA gene of B. xylophilus was selected as a reference gene. The RNAi treatment resulted in down-regulation of the endo$\beta$-1,4-glucanase mRNA (Figure 4). The mRNA expression in nematodes after treatment with siRNA ${ }^{15}$, siRNA ${ }^{275}$, siRNA ${ }^{356}$, and siRNA ${ }^{581}$ was $70.5,70.2,55.9$, and $8.70 \%$ lower than in the control, respectively. The potential for gene silencing of the various dsRNAs differed. Consequently, an RNAi experiment should be performed before testing designed siRNA sequences.



Figure 4. mRNA expression of the cellulase gene in Bursaphelenchus xylophilus after soaking in different siRNA solutions. 


\section{Cellulase activity assay}

Cellulose digestion requires cellulase, including endo- $\beta$-1,4-glucanase, exo- $\beta-1,4-$ glucanase and $\beta$-glycosidase. The cellulase activity of the pine wood nematodes was detected after they were treated with dsRNA solution. The activity of exo- $\beta-1,4$-glucanase and $\beta$-glycosidase was not significantly different after treatment with the various siRNAs (data not shown). However, various siRNAs resulted in significantly different endo- $\beta$-1,4-glucanase activity (Figure $5 ; \mathrm{P}<$ 0.01 ). The activity of endo- $\beta-1,4$-glucanase from the control nematodes was higher, up to 11.27 $\mu \mathrm{g} \cdot \mathrm{mL}^{-1} \cdot \mathrm{min}^{-1}$, while that from the siRNA ${ }^{15}$-treated nematode secretion was the lowest, being only $5.27 \mu \mathrm{g} \cdot \mathrm{mL}^{-1} \cdot \mathrm{min}^{-1}$. The cellulase activity results showed that dsRNA inhibited expression of the endo- $\beta-1,4$-glucanase gene and decreased endo- $\beta-1,4$-glucanase activity.

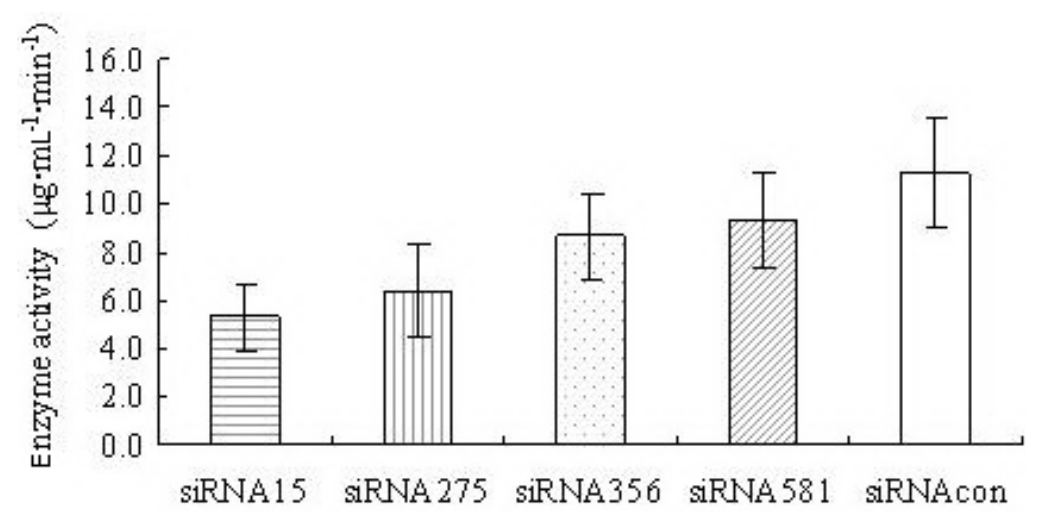

Figure 5. Activity of secreted endo- $\beta-1,4$-glucanase of Bursaphelenchus xylophilus after soaking in different siRNA solutions and the control solution. Bars show the standard error of the mean. Significant difference were found between the siRNAs and the control $(\mathrm{P}<0.01)$.

\section{Dispersal of B. xylophilus}

The fasted untreated nematodes crossed the branch section after $30 \mathrm{~h}$. The nematodes treated with siRNA ${ }^{356}$ solution crossed the section in $132 \mathrm{~h}$, and the number of nematodes passing through the branch section was significantly higher in the control compared with those treated with the dsRNA treatment (Table 2). Inhibition of the expression of the endo- $\beta-1,4-$ glucanase gene negatively influenced the dispersal ability of the $B$. xylophilus in the branch section of P. thunbergii.

\begin{tabular}{lcc}
\multicolumn{2}{c}{ Table 2. Effect of siRNA treatment on Bursaphelenchus xylophilus passing through the branch sections of Pinus thunbergii. } \\
\hline siRNA & Detected time (h) & Number of nematodes \\
\hline siRNA $^{15}$ & 80 & $5.3 \pm 1.2^{\mathrm{b}}$ \\
siRNA $^{275}$ & 96 & $4.0 \pm 1.0^{\mathrm{b}}$ \\
siRNA $^{356}$ & 132 & $3.7 \pm 0.6^{\mathrm{b}}$ \\
siRNA $^{581}$ & 78 & $3.3 \pm 2.3^{\mathrm{b}}$ \\
siRNA $^{\text {con }}$ & 30 & $8.3 \pm 1.5^{\mathrm{a}}$ \\
\hline
\end{tabular}

Means followed by the same superscript letters in each column are not significantly different at the $5 \%$ level. 


\section{DISCUSSION}

RNAi is the phenomenon of post-transcriptional gene silencing resulting from dsRNA. Since RNAi was first discovered in C. elegans in the 1990s, it became one of the most important tools in biological and medical research concerning gene function, gene silencing, and gene therapy (Guo and Kemphues, 1995). Recent studies have provided evidence of the efficacy of RNAi in controlling plant parasitic nematodes (Lilley et al., 2007). RNAi has been used to investigate gene function in B. xylophilus (Wang et al., 2007; Park et al., 2008). RNAi offers the possibility to analyze gene function in vitro on a routine basis; although the molecular biology of the interactions between B. xylophilus and its host at a molecular level and the molecular basis of the pathogenicity of the nematode are still poorly understood (Jones et al., 2008).

Park et al. (2008) compared three methods of transferring dsRNA into B. xylophilus and found that microinjection was the most efficient, compared to soaking and electroporation. Octopamine, resorcinol and serotonin were used to induce ingestion of dsRNA from the soaking buffer by plant parasitic root-knot nematodes (Urwin et al., 2002; Rosso et al., 2005; Bakhetia et al., 2007; Shingles et al., 2007). The addition of spermidine to the soaking buffer and an extended incubation time were reported to increase the efficiency of RNAi for Globodera rostochiensis and B. xylophilus (Chen et al., 2005; Park et al., 2008). Wang et al. (2007) reported that soaking in dsRNA solution targeted to RNA polymerase reduced B. xylophilus reproduction. We found that changes in incubation conditions can help increase uptake of dsRNA by B. xylophilus, especially the time to select highly efficient siRNA sequences for RNAi tests.

We found that RNAi decreases the expression of endo- $\beta$-1,4-glucanase gene in B. xylophilus delays. When pine wood nematodes are soaked in dsRNA they take longer to migrate through branch sections of $P$. thunbergii. Differences between trees in the inhibition of dispersal and between-isolate differences in the dispersal ability of $B$. xylophilus have been reported (Matsunaga and Togashi, 2004). Silencing of the endo- $\beta-$ 1,4-glucanase gene with RNAi resulted in reducing the ability to locate and invade roots and decreased the number of established nematodes (Chen et al., 2005; Bakhetia et al., 2007). Huang et al. (2006) reported that soaking second-stage juveniles (J2) of plant parasitic nematodes targeting to secreted peptide $16 \mathrm{D}$ reduced galling and decreased the number of established nematodes.

However, in this case, the siRNA oligos were synthesized based on the target sequence and the synthesized siRNA efficiency remained constant during the test. The efficiency of applying RNAi by soaking was reduced after inoculating into branches of a susceptible host for 20 days (Cheng et al., 2010). Molecular biology has provided new perspectives for research on pine wood nematodes and their interaction with their host.

\section{ACKNOWLEDGMENTS}

Research supported by the Common Weal Research Program for Forestry (\#200904061) and the International S\&T Cooperation Program of China (\#2007DFB30270).

\section{REFERENCES}

Bakhetia M, Urwin PE and Atkinson HJ (2007). QPCR analysis and RNAi define pharyngeal gland cell-expressed genes of Heterodera glycines required for initial interactions with the host. Mol. Plant Microbe Interact. 20: 306-312. 
Chen Q, Rehman S, Smant G and Jones JT (2005). Functional analysis of pathogenicity proteins of the potato cyst nematode Globodera rostochiensis using RNAi. Mol. Plant Microbe Interact. 18: 621-625.

Cheng XY, Dai SM, Xiao L and Xie BY (2010). Influence of cellulase gene knochdown by dsRNA interference on the development and reproduction of the pine wood nematode, Bursaphelenchus xylophilus. Nematology 12: 225-233.

Fanelli E, Di Vito M, Jones JT and De Giorgi C (2005). Analysis of chitin synthase function in a plant parasitic nematode, Meloidogyne artiellia, using RNAi. Gene 349: 87-95.

Fire A, Xu S, Montgomery MK, Kostas SA, et al. (1998). Potent and specific genetic interference by double-stranded RNA in Caenorhabditis elegans. Nature 391: 806-811.

Guo S and Kemphues KJ (1995). Par-1, a gene required for establishing polarity in C. elegans embryos, encodes a putative Ser/Thr kinase that is asymmetrically distributed. Cell 81: 611-620.

Huang G, Allen R, Davis EL, Baum TJ, et al. (2006). Engineering broad root-knot resistance in transgenic plants by RNAi silencing of a conserved and essential root-knot nematode parasitism gene. Proc. Natl. Acad. Sci. U. S. A. 103: $14302-14306$.

Jones JT, Moens M, Mota M, Li H, et al. (2008). Bursaphelenchus xylophilus: opportunities in comparative genomics and molecular host-parasite interactions. Mol. Plant Pathol. 9: 357-368.

Kikuchi T, Jones JT, Aikawa T, Kosaka H, et al. (2004). A family of glycosyl hydrolase family 45 cellulases from the pine wood nematode Bursaphelenchus xylophilus. FEBS Lett. 572: 201-205.

Kikuchi T, Shibuya H and Jones JT (2005). Molecular and biochemical characterization of an endo- $\beta-1,3$-glucanase from the pinewood nematode Bursaphelenchus xylophilus acquired by horizontal gene transfer from bacteria. Biochem. J. 389: 117-125.

Kikuchi T, Shibuya H, Aikawa T and Jones JT (2006). Cloning and characterization of pectate lyases expressed in the esophageal gland of the pine wood nematode Bursaphelenchus xylophilus. Mol. Plant Microbe Interact. 19: $280-287$.

Kikuchi T, Aikawa T, Kosaka H, Pritchard L, et al. (2007). Expressed sequence tag (EST) analysis of the pine wood nematode Bursaphelenchus xylophilus and B. mucronatus. Mol. Biochem. Parasitol. 155: 9-17.

Kiyohara T and Tokushige Y (1971). Inoculation experiments of a nematode, Bursaphelenchus sp., onto pine trees. J. Jpn. For. Soc. 53: 210-218.

Kuroda K (1989). Terpenoids causing tracheid-cavitation in Pinus thunbergii infected by the pine wood nematode (Bursaphelenchus xylophilus). Ann. Phytopath. Soc. Jpn. 55: 170-178.

Li YH, Guo R, Yin QY, Ding M, et al. (2005). Purification and characterization of two endo- $\beta-1,4$-glucanases from mollusca, Ampullaria crossean. Acta Biochim. Biophys. Sin. 37: 702-708.

Lilley CJ, Bakhetia M, Charlton WL and Urwin PE (2007). Recent progress in the development of RNA interference for plant parasitic nematodes. Mol. Plant Pathol. 8: 701-711.

Mamiya Y (1983). Pathology of pine wilt disease caused by Bursaphelenchus xylophilus. Annu. Rev. Phytopathol. 21: 201-220.

Mamiya Y and Enda N (1972). Transmission of Bursaphelenchus lignicola (Nematoda: Aphelenchoidae) by Monochamus alternatus (Coleopteran: Cerambycidae). Nematologica 18: 159-162.

Mamiya Y and Kiyohara T (1972). Description of Bursaphelenchus lignicolus sp (Nematoda: Aphelenchoididae) from pine wood and histopathology of nematode-infested trees. Nematologica 18: 120-124.

Matsunaga K and Togashi K (2004). Among-tree difference in the inhibition of systemic dispersal of Bursaphelenchus xylophilus (Nematoda: Aphelenchoididae) by Pinus densiflora. Appl. Entomol. Zool. 39: 271-277.

Odani K, Sasaki S, Nishiyama Y and Yamamoto N (1985). Early symptom developments of the pine wilt disease by hydrolytic enzymes produced by the pine wood nematodes-cellulase as a possible candidate of the pathogen. J. Jpn. For. Soc. 67: 366-372.

Park JE, Lee KY, Lee SJ, Oh WS, et al. (2008). The efficiency of RNA interference in Bursaphelenchus xylophilus. Mol. Cells 26: 81-86.

Rosso MN, Favery B, Piotte C, Arthaud L, et al. (1999). Isolation of a cDNA encoding a $\beta-1,4-$ endoglucanase in the rootknot nematode Meloidogyne incognita and expression analysis during plant parasitism. Mol. Plant Microbe Interact. 12: $585-591$.

Rosso MN, Dubrana MP, Cimbolini N, Jaubert S, et al. (2005). Application of RNA interference to root-knot nematode genes encoding esophageal gland proteins. Mol. Plant Microbe Interact. 18: 615-620.

Shingles J, Lilley CJ, Atkinson HJ and Urwin PE (2007). Meloidogyne incognita: molecular and biochemical characterisation of a cathepsin L cysteine proteinase and the effect on parasitism following RNAi. Exp. Parasitol. 115: 114-120.

Togashi K and Matsunaga K (2003). Between isolate difference in dispersal ability of Bursaphelenchus xylophilus and vulnerability to inhibition by Pinus densiflora. Nematology 5: 559-564. 
Tokushige Y and Kiyohara T (1969). Bursaphelenchus sp. in the wood of dead pine trees. J. Jpn. For. Soc. 51: 193-195. Urwin PE, Lilley CJ and Atkinson HJ (2002). Ingestion of double-stranded RNA by pre parasitic juvenile cyst nematodes leads to RNA interference. Mol. Plant Microbe Interact. 15: 747-752.

Wang SX, Niu BL, Shen WF and Weng HB (2007). RNA interference of RNA polymerase gene in Bursaphelenchus xylophilus. Zhejiang Agric. Sci. 6: 690-693.

Zhang XY and Luo YQ (2006). Major Forest Disease and Insect Pests in China. Chinese Publishing House of Forestry, Beijing. 